May - 2021

\title{
Parents' Perceptions of Their Children's Experiences With Distance Learning During the COVID-19 Pandemic
}

Dr. Diala A. Hamaidi' 1 , Dr. Yousef M. Arouri2, Rana K. Noufal ${ }^{3}$, and Islam T. Aldrou ${ }^{4}$

${ }^{1}$ Department of Psychological Sciences, Qatar University; ${ }^{2}$ Department of Curriculum and Instruction, University of Jordan, Jordan; ${ }^{3}$ United Nations Relief and Works Agency, Jordan; ${ }^{4}$ Jordan Radio and Television Corporation, Jordan

\begin{abstract}
This study aimed to investigate the perceptions of primary and secondary students' parents in Jordan toward the distance learning process implemented in light of the coronavirus disease (COVID-19) pandemic. To achieve the study objectives, the researchers used the descriptive survey method to collect and analyze data and interpret the results. After developing the study instrument (questionnaire) and ensuring its validity and reliability, it was distributed to a selected sample, consisting of 470 parents, by random cluster method during the second semester of the 2019-2020 academic year. The study results show that primary and secondary students' parents were moderately satisfied with the distance learning process implemented in light of the COVID-19 pandemic. In addition, the results reveal statistically significant differences in the parents' perceptions attributed to the variables of the child's grade, in favor of grades 5-7; teacher's gender, in favor of female teachers; and school type, in favor of private schools.
\end{abstract}

Keywords: parents' perceptions, primary/secondary students, distance learning, COVID-19 pandemic, Jordan 


\section{Introduction}

Jordan, like the rest of the world, has faced the coronavirus disease (COVID-19) pandemic by making rapid and firm decisions that have helped limit the spread of the virus. These decisions have included imposing curfews across the country and forcing people to stay in their homes. The impact of such decisions has resulted in the closure of all schools and the suspension of the teaching and learning process in its traditional form: face to face. Under these circumstances, educational officials have sought to find optimal alternative teaching and learning methods that contribute to the sustainability of the teaching and learning process. The solution was a digital transformation in teaching and learning and the use of digital applications to accomplish distance learning or Web-based learning. This study reveals the perceptions of primary and secondary students' parents toward their children's distance learning in light of the COVID-19 pandemic.

The advent of the Internet has contributed to enhancing learning opportunities; such a network has an enormous ability to support effective and quick communication in different forms between parties. In addition, this network has the potential to help people solve problems, enhance research and investigation, and make the educational process fruitful (Saadeh \& Al-Sartawi, 2015). Aboud (2007) and Al-Ghannouchi (2010) demonstrate that the Internet has beneficial uses in the educational field, such as allowing people to keep up with modern developments in the world and providing people with new educational opportunities to address the problem of population explosion. Aboud (2007) asserts that using the Internet has enabled teachers and learners to play new roles. That is, teachers are no longer the only initiators or the only source of information or knowledge. Rather, they have become researchers who seek to pursue professional developments in their fields of specialization. As for learners, they are no longer just the recipients who memorize and store information: they have become active researchers and learners as well.

Bin Ahmed et al. (2019) and Al-Arfaj et al. (2012) explain that Internet technology has helped in education development in general and distance learning in particular; the Internet has helped move distance learning from primitive correspondence through traditional mail, without any interaction between learner and teacher, to more advanced open learning. Al-Smadi (2020) affirms that open learning focuses on the use of Web technology as one source of the knowledge revolution, using applications such as videoconferences, simulation systems, and virtual classes, which all have helped in achieving communication between teachers and learners through learning systems and social networks.

\section{Distance Learning}

Distance learning is defined as an educational system that helps teachers organize and manage learning and teaching processes and enhances teachers' communication with learners, regardless of place and time, through the use of electronic or print media (UNESCO, 2002). Amer (2013) explains that distance learning is a group learning system open to all without the restrictions of time and space or the group of learners; this type of education is appropriate for the nature and needs of all members of society. Awad and Hilles (2015) explain that distance learning comprises a set of electronic educational systems that allows learners to interact freely with electronic resources related to topics and courses important to them, whether through mobile learning, classrooms, blogs, or other mediums. 
Al-Najem (2019) adds that distance learning is a way of learning in which learners receive knowledge by using applications and various means of communication that may include simple printed materials or more advanced materials sent over the Web. Al-Smadi (2020) stresses that distance learning is a learning method where the learner uses modern communication means such as computers, networks, research engines, Internet portals, and multimedia such as pictures, sound, and graphics. In sum, the current study's researchers found that the definitions of distance learning terms have focused on specific aspects affirmed by Amer (2013). First is the physical separation of the teacher from the learner: the communication between the teacher and the learner becomes indirect, which helps students learn at their own speed, in any place, and at any time that suits their circumstances and needs. Second is the role of effective modern media and communication tools in transferring learning to students using multiple educational media, whether through printed, electronic, recorded, or visual materials.

\section{Distance Learning Importance and Challenges}

Al-Najem (2019) explains that the formation and development of distance learning went through several stages. First, in the mid-19th century, a few universities began to send their educational materials by mail to learners in their homes, and thus the process of distance learning began. Second, in the mid-2oth century, the technological development of various means of communication helped advance distance learning; learners received their education through television and radio broadcasts. Third, in the late 200os, learners started using more modern technological means such as computers to receive various educational content. Fourth, at the beginning of the 21st century, it became easy for learners to obtain all necessary audio or visual study materials through computer programs recorded on CDs, through satellite broadcasting, or via the Internet. There is now no need to attend educational institutions; rather, teachers and students can communicate and participate in various educational meetings online.

Al-Smadi (2020) shows that distance learning has become one of the easiest ways to learn because it is in line with current trends and learners' tendencies. In addition, integrating technology into the classroom has not only helped learners to learn better but also enabled them to acquire various skills of great importance, such as technological skills. Amer (2013) explains that the importance of distance learning lies in the following: (a) making educational opportunities available to everyone regardless of spatial or temporal obstacles, (b) enabling students to learn according to their own abilities and circumstances, and (c) allowing students to choose how to receive study materials individually and based on their own learning styles. Al-Rashidi (2018) adds that distance learning increases interactions between teachers and students, especially those who are ashamed to interact face to face. In addition, distance learning brings students in remote areas equal opportunities to acquire the same access to education that is available to urban students (Hamaidi, 2008).

Despite the positive benefits of distance learning in facilitating learning and teaching, many challenges contribute to limiting the effectiveness of its application in an optimal way. Some of these challenges include the following. First is the challenge of designing educational content; teachers face obstacles when preparing digital or printed educational material in ensuring that they will be sufficient for learners achieve learning goals with high efficiency. Further, teachers face hardships in choosing teaching strategies and methods that take into account students' different learning needs and patterns, as well as in choosing appropriate tools to measure student learning (Al-Mukhaini, 2017; Al-Rawadiyah 
et al., 2014; Al-Sajini \& Khalil, 2017). Second is the difficulty in implementing distance learning. Some teachers face difficulties in monitoring, following up with, and evaluating students; in appropriate time management; and in working with learners who are not engaged with the learning process, which improves the feeling of more prevalent isolation in this learning environment (Al-Sharman, 2015). Third is the availability of technology. Some difficulties faced include providing devices, applications, and technical support; the efficiency and speed of one's Internet connection; and teachers' and students' insufficient skills in using these technologies and applications (Lever-Duffy \& McDonald, 2018). Fourth is administrative responsibility: this includes all administrative problems that occur during distance learning, such as administrators' and officials' lack of awareness of several factors, such as the importance of this type of learning, its requirements, and how it works (Al-Areifi et al., 2016).

\section{Theoretical Framework}

This study's researchers drew on their interpretation of the distance learning process based on Holmberg's $(1983,1995)$ ideas and assumptions. Holmberg (1983) explains that distance learning (a) supports the learner's motivation and enhances their enjoyment of learning; (b) links individual learners with their subjectivity and their diverse needs, which includes a distinguished relationship between learners and the educational institution that provides distance education supports such as teachers, counselors, and assistants; (c) helps learners deal with educational content and integrates the learner in various educational activities, discussions, and decision making; and (d) helps strengthen real communication and assumptions between the system and all its components and students. Holmberg (1983) observed that his theory of distance learning had an interpretative value in linking the effectiveness of teaching to the influence of feelings about cooperation and affiliation, especially when questions, answers, and discussions are exchanged across different communication media.

Holmberg (1995) presented his theory of distance learning through "interaction and communication theory," which is based on seven basic assumptions and principles. First, teaching revolves around the interaction between the two sides of learning and education. That is, the interaction occurs through the learning of content presented in previous courses; learners interact with these curricula by offering views and presenting different solutions using various methods of thinking. Second, the emotional involvement in learning and the involvement of feelings in personal relationships between the parties to the learning and teaching process contribute to increasing pleasure in learning. Third, enjoyment in learning contributes to increasing the learner's motivation. Fourth, participation in learning decisions can also increase the learner's motivation. Fifth, motivation facilitates learning. Sixth, the harmony of the learning process with the content contributes to increasing the fun of learning and supporting the learner's motivation to learn. Seventh, the effectiveness of teaching is demonstrated by students' learning of what has been taught. Schlosser and Simonson (2015) assert that earlier assumptions are seen as the basic principles of effective distance learning, which makes it easier for students to learn concepts and solve problems by organizing and implementing them in a way in which they are encouraged to research and criticize and appreciate their potentials.

This study attempts to learn more about the implications of the interaction and communication theory by uncovering the perceptions of parents who observe their children's interactions with distance learning during the COVID-19 pandemic. It is crucial to investigate parents' perceptions, as observers 
of this new learning experience and its impact on their children, because they describe the climate and enthusiasm for this educational experience.

\section{Previous Studies}

Many research studies have revealed the perceptions of administrators, teachers, and students toward distance learning in educational institutions. Among studies related to teachers' perceptions, Al-shboul et al.'s (2015) study aimed to reveal the perceptions of faculty members at Yarmouk University in Jordan regarding the application of distance learning in virtual environments. The researchers drew on the descriptive approach to collecting data from 91 faculty members in the 2013-2014 academic year. Faculty members gave distance education in virtual environments a good score. Further, Al-shboul et al. show statistically significant differences attributed to the age variable, in favor of a younger age, as well as the department variable, in favor of the departments of curriculum and instruction and educational administration. The researchers found no statistically significant differences attributed to the variables of experience years and gender.

In the same context, Aqel (2014) aimed to reveal the attitudes of faculty members in Jordanian public universities toward distance learning and its relationship to some variables. The study included 298 faculty members from all academic levels in 2013-2014. University of Jordan faculty members' attitudes toward distance learning were moderately positive. Further, no statistically significant differences were attributed to academic rank; however, statistically significant differences were attributed to the variable of academic specialization, in favor of medical colleges, over human colleges, followed by scientific colleges. Furthermore, Aqel's (2014) results reveal many obstacles that limit the possibility of applying distance learning in public universities in Jordan.

Among studies that reveal learners' perceptions is Rajadurai et al.'s (2018) study, which aimed to reveal students' satisfaction and their level of performance in the online learning environment in Malaysian universities of open and distance learning (ODL). The researchers used the descriptive-analytical method. A questionnaire was distributed to 2,283 students from ODL universities. The results reveal a significant positive correlation between students' performance and satisfaction with the educational content, evaluation management, and services provided by universities. However, only two variables were related to learners' performance-namely, evaluation management and services provided by universities.

In the same context, Awad and Hilles (2015) have revealed the attitudes among graduate students in Palestinian universities toward distance learning technology and its relationship to some variables. The researchers used the descriptive-analytical method. The sample consisted of 91 students studying in graduate programs at colleges of education in Palestinian universities. Results reveal positive attitudes toward distance learning technology among graduate students in Palestinian universities. Further, they show no statistically significant differences in students' responses to distance learning technology according to variables of gender, educational level, and general estimate of the importance of distance learning technology.

By reviewing previous studies, the current study's researchers concluded, to their knowledge, that studies held over the last nine years in Jordan examining perceptions of distance learning are limited; the last study found took place in 2015. In addition, these studies reveal the perceptions of faculty 
members in Jordanian universities, but no studies reveal the perceptions of primary and secondary students and their parents toward distance learning in Jordan. The current study is considered the first study, according to the researchers' knowledge, that examines parents' perceptions of their children's experiences in primary and secondary education with distance learning during the COVID-19 pandemic.

\section{Problem and Questions}

With the COVID-19 pandemic, most countries of the world, including Jordan, have been forced to implement strict procedures and make difficult decisions to help limit the spread of the virus. Jordan imposed a quarantine on the citizens and made the decision to disrupt face-to-face learning and teaching in all public and private schools. It was thus necessary to adopt a new educational system to ensure the continuation of the learning and teaching processes. Therefore, Jordan's Ministry of Education decided to implement a distance learning system in all public and private schools that cover primary and secondary grades. This system's application was accompanied by many questions related to the extent of its effectiveness and the feasibility of its application compared with traditional education, as well as questions related to the challenges that contribute to reducing its success, whether related to technological skills, physical equipment, infrastructure, or distance learning design skills that teachers should possess (Ministry of Education, 2020b).

Since parents are at the forefront of responsibility for their children's learning, and because they are the true observers of children in the distance learning environment, it is necessary to evaluate the parents' viewpoints of their children's experience using the distance learning system during the COVID-19 pandemic. Therefore, this study came to investigate the following questions:

1. What are the perceptions of parents of primary and secondary students in Jordan toward the distance learning process in light of the COVID-19 pandemic?

2. Are there statistically significant differences at the level of significance $(\alpha=.05)$ in perceptions of parents of primary and secondary students in Jordan toward the distance learning process attributed to the variable of the child's grade?

3. Are there statistically significant differences at the level of significance $(\alpha=.05)$ in perceptions of parents of primary and secondary students in Jordan toward the distance learning process attributed to the variable of teacher's gender?

4. Are there statistically significant differences at the level of significance $(\alpha=.05)$ in perceptions of parents of primary and secondary students in Jordan toward the distance learning process attributed to the variable of school type?

\section{Objectives and Importance}

This study's aim was to investigate the perceptions of parents of primary and secondary students in Jordan regarding the distance learning process. Further, it aimed to identify the statistically significant differences $(\alpha=.05)$ related to the perceptions of parents of primary and secondary students in Jordan 
of the distance learning process in relation to the variables of child's grade, teacher's gender, and school type.

This study discusses one of the most important current questions in the educational field in Jordan. It reveals the reality of implementing a distance learning process from the viewpoints of learners' parents. The researchers hope that the results of this study will encourage teachers to optimize the application of distance teaching, to seek to improve the distance learning experience, and to further develop its application according to students' needs. This study can help decision makers and specialists in the education sector learn more about the distance learning experience and improve its use in the future in a manner that meets students' needs. The authors expect that this study may inform decision makers and managers in the educational sector about the perceptions of parents of primary-/secondaryeducation students toward this new learning educational experience. Knowledge of such perceptions can provide opportunities to reinforce the positive aspects of the application and address its negative aspects. This study is expected to open new opportunities for researchers to conduct quantitative and qualitative research related to students' and teachers' perceptions of distance learning in both schools and universities.

\section{Procedural Definitions}

Distance learning: An e-learning environment in which primary/secondary students in Jordan obtain knowledge, skills, and attitudes they need without the need for teachers to be with them in the same place or at the same time.

Parents: The fathers, mothers, or guardians who are responsible for their children in primary or secondary school in Jordan, as well as for their learning affairs at homes and schools.

Primary/secondary school students: First-grade to tenth-grade students in public, private, and United Nations Relief and Works Agency (UNRWA) schools in Jordan, whose ages range from 6 to 16 years.

COVID-19 pandemic: The effects of the spread of the COVID-19 virus, which can cause illness in humans, which has resulted in the disruption of the traditional, face-to-face learning and teaching process and its replacement using a distance learning system.

Parents' perceptions: A knowledge system for parents of primary and secondary school students resulting from mental activity that includes their values, ideas, opinions, and attitudes toward their children's experiences in a distance learning environment during the COVID-19 pandemic. These perceptions are measured by the degree that the respondent gets on the study instrument.

\section{Limitations and Delimitations}

This study is limited to identifying the perceptions of parents of primary- and secondary-education students, in public, private, and UNRWA schools in Jordan, regarding the distance learning process during the COVID-19 pandemic. Further, this study was conducted after the second semester of the 2019-2020 academic year ended. Results were determined by the reliability and validity of the study instrument, as well as the sample individuals' responses. 


\section{Methodology}

The researchers used the descriptive survey method to reveal the perceptions of parents of primary and secondary students in Jordan of the distance learning process during the COVID-19 pandemic. This method is based on an accurate interpretation of the phenomenon or problem, with the aim of arriving at an accurate and integrated scientific description through data analysis, to generalize the facts or knowledge that were extracted (Al-Manizel \& Al-Atoom, 2010).

\section{Population and Sample}

The study population consisted of all parents of primary and secondary school students in all governorates of Jordan during the second semester of the 2019-2020 academic year. To achieve the study aims, a cluster randomized method was used to select the study sample, which consisted of 470 parents of primary/secondary students. The parents in the sample were males and females from all regions of northern, central, and southern Jordan. They possessed various academic diplomas and degrees, such as high school diplomas, intermediate diplomas, bachelor's degrees, master's degrees, and doctorate degrees. The parents also have children, male or female, in various grades $(1-4,5-7,8-$ 10), who study in public, private, or UNRWA schools.

\section{Instrument}

The researchers reviewed theoretical literature and previous studies (e.g., Al-shboul et al., 2015; Rajadurai et al., 2018) to develop a questionnaire in order to collect necessary data to answer the study questions. The questionnaire consisted of two parts: the first section was designed to collect demographic information, and the second section included various items that measured the parents' perceptions of the primary/secondary students' learning. Specifically, the second section consisted of two fields. The first field measured the parents' perceptions about themselves, and it was divided into five dimensions (28 items). The second field measured the parents' perceptions about their children's learning, and it was divided into four dimensions (28 paragraphs). In its final form, the questionnaire contained 56 items rated on a Likert-type (five-point) scale: 1 =very low, 2 = low, 3 = medium, $4=$ high, and very $5=$ very high. The study adopted the following weights to measure parents' perceptions of the distance learning process: a high degree for the items whose means were greater than 3.66, a medium degree for the items whose means ranged between 3.66 and 2.34, and a low degree for the items whose means were less than 2.34 .

\section{Validity and Reliability}

The content and validity of the study instrument were checked by presenting the instrument's initial form to a number of experts (12) in the fields of curricula and teaching, educational technology, and measurement and evaluation. These experts critiqued questionnaire items based on their harmony with the study objectives, the integrity and clarity of the linguistic formulation, and the affiliation of the domain under which they were classified. Amendments were made according to comments agreed on by $80 \%$ of the arbitrators and experts. Most amendments were limited to items' language and wording. In addition, the researchers checked the reliability of the study instrument by calculating internal consistency using Cronbach's alpha after applying the questionnaire to an exploratory sample (31) from the study community and outside the study sample. The reliability coefficients for the dimensions of the study instrument came as follows: dimension $1.1=0.88$, dimension $1.2=0.88$, dimension $1.3=0.78$, dimension $1.4=0.90$, dimension $1.5=0.89$, dimension $2.1=0.85$, dimension $2.2=0.92$, dimension $2.3=0.91$, and dimension $2.4=0.95$. 


\section{Variables and Statistical Treatments}

This study included one dependent variable-parents' perceptions of primary/secondary students' learning-and three independent variables-child's grade (1-4, 5-7, 8-10), teacher's gender (male, female), and school type (public, private, UNRWA). The researchers used several statistical methods to analyze the collected data and to answer the study questions. Means and standard deviations were calculated to answer all study questions; one-way analysis of variance (ANOVA) and Schiff's post hoc tests were used to answer the second and fourth questions; and the independent samples $t$ test was used to answer the third question.

\section{Results and Discussion}

\section{First Question}

To answer the first question - what are the perceptions of parents of primary and secondary students in Jordan toward the distance learning process in light of the COVID-19 pandemic? -means and standard deviations were calculated. Table 1 shows the results according to the research instrument's fields and dimensions.

\section{Table 1}

Means and Standard Deviations of Parents' Perceptions Toward the Distance Learning Process

\begin{tabular}{|c|c|c|c|}
\hline Field/dimension & $M$ & $S D$ & $\begin{array}{l}\text { Degree of } \\
\text { perception }\end{array}$ \\
\hline Field 1. Parents' perceptions of themselves & 3.5660 & 1.10287 & Medium \\
\hline $\begin{array}{l}\text { Dimension 1.1. Perceptions related to the physical } \\
\text { components and the distance learning environment }\end{array}$ & 3.6755 & 0.74423 & High \\
\hline Dimension 1.2. Perceptions related to technological skills & 3.5819 & 1.09816 & Medium \\
\hline Dimension 1.3. Perceptions related to cooperative skills & 3.9447 & 0.93961 & High \\
\hline $\begin{array}{l}\text { Dimension 1.4. Perceptions related to communicating } \\
\text { with members of the distance learning environment }\end{array}$ & 2.8862 & 0.95100 & Medium \\
\hline $\begin{array}{l}\text { Dimension 1.5. Perceptions related to the nature of the } \\
\text { distance learning process and the content presented } \\
\text { therein }\end{array}$ & 3.5000 & 1.10291 & Medium \\
\hline Field 2. Parents' perceptions of their children's learning & 3.4404 & 1.15516 & Medium \\
\hline $\begin{array}{l}\text { Dimension 2.1. Perceptions related to possessing } \\
\text { technological skills }\end{array}$ & 3.6128 & 1.10003 & Medium \\
\hline $\begin{array}{l}\text { Dimension 2.2. Perceptions related to commitment to } \\
\text { ethics during distance learning }\end{array}$ & 3.9351 & 0.85677 & High \\
\hline Dimension 2.3. Perceptions related to cooperative skills & 2.9191 & 1.07742 & Medium \\
\hline $\begin{array}{l}\text { Dimension 2.4. Perceptions related to developing self- } \\
\text { learning skills }\end{array}$ & 3.2426 & 1.19152 & Medium \\
\hline Average & 3.4064 & 1.12292 & Medium \\
\hline
\end{tabular}

Table 1 shows that primary and secondary students' parents had a medium degree of perception toward the distance learning process during the COVID-19 pandemic $(M=3.4064, S D=1.12292)$. Further, 
parents' perceptions of themselves were rated as medium $(M=3.5660, S D=1.10287)$. Means of items in this field ranged between 2.8862 and 3.9447, and all dimensions had a medium degree of perception. These results indicate that parents were satisfied and accepted the process of distance learning. However, they felt more satisfied with the first (1.1. perceptions related to the physical components and the distance learning environment) and third dimensions (1.3. perceptions related to cooperative skills), which were rated highly. This finding shows parents' favorable perceptions of the presented physical components and the cooperation skills children received via distance education during the COVID-19 pandemic.

Furthermore, Table 1 shows that parents had a medium perception of their children's learning $(M=3.4404, S D=1.15516)$. Means of items in this field ranged between 2.9191 and 3.9351. All dimensions were rated medium. That is, parents felt satisfied in general regarding their children's learning process during the pandemic. However, the second dimension (2.2. perceptions related to commitment to ethics during distance learning) was rated highly. This finding describes the parents' high level of interest in the ethical climate of distance learning and their readiness to accommodate this type of educational experience.

The medium degree of perception found indicates the satisfaction level perceived by parents. It can be attributed to the circumstances in which the distance learning process was applied suddenly and without any advance preparation or training for teachers and students to learn how to use it. However, during the pandemic, the Ministry of Education in Jordan intensified its efforts and launched a multieducational platform, Noorspace (Ministry of Education, 2020c), allocating satellite channels to broadcast lessons for different classes and subjects, and urged teachers and students to use multiple applications such as Microsoft applications, including Teams and Forms, to sustain the teaching and learning processes. The Ministry of Education also launched a training program for teachers consisting of 90 training hours aimed at sustaining their professional development to ensure success of the distance learning process with all its components (Ministry of Education, 2020a). Such procedural steps initiated by the Ministry of Education have helped parents form an acceptable perception toward distance learning, even though students and teachers in all Jordanian schools had never previously had such an experience.

The abovementioned results, where parents rated their perception as high, including perceptions about the extent to which parents provided the physical components in the distance learning environment, the extent of their cooperation with their children to sustain teaching and learning processes, and the extent that they verified their children's commitment to ethics during distance learning, can be attributed to the following: (a) the parents' satisfaction with themselves in sustaining their children's learning, (b) their invested financial capabilities to provide the physical components needed to sustain their children's learning, and (c) their great efforts in helping their children achieve their educational goals. Through this study, researchers in the educational field found a disparity between parents in their financial capabilities and their cooperation with children in sustaining the teaching and learning processes. However, parents are satisfied with their performance because they think that they did their best with their available capabilities.

Regardless of the compatibility of the sample, which included parents who were in the samples of previous studies that included teachers and students in universities, the results of this study are consistent with results from previous studies (e.g., Al-shboul et al., 2015; Aqel, 2014; Awad \& Hilles, 
2015; Rajadurai et al., 2018). This indicates that perceptions and attitudes toward distance learning were moderately positive.

\section{Second Question}

To answer the second question-are there statistically significant differences at the level of significance $(\alpha=.05)$ in the perceptions of parents of primary and secondary students in Jordan toward the distance learning process attributed to the child's grade variable?-means and standard deviations were calculated. Table 2 shows these results according to the child's grade level $(1-4,5-7,8-10)$.

\section{Table 2}

Means and Standard Deviations of Parents' Perceptions Toward the Distance Learning Process According to Child's Grade Level

\begin{tabular}{lcc}
\hline Child's grade level & $M$ & $S D$ \\
\hline $1-4$ & 3.0500 & 0.87571 \\
$5-7$ & 3.7454 & 1.24918 \\
$8-10$ & 3.1895 & 0.94480 \\
Average & 3.4064 & 1.12292 \\
\hline
\end{tabular}

Table 2 illustrates that there are apparent differences between means according to the child's grade level. To find out whether these differences are statistically significant, the one-way ANOVA test was calculated. Results are illustrated in Table 3.

\section{Table 3}

One-Way ANOVA of Parents' Perceptions Toward the Distance Learning Process According to Child's Grade Level

\begin{tabular}{lccccc}
\hline \multicolumn{1}{c}{ Source } & Type III sum of squares & $d f$ & $M S$ & $F$ & Sig. \\
\hline Between groups & 47.164 & 2 & 23.582 & 20.236 & .000* $^{*}$ \\
Within groups & 544.217 & 467 & 1.165 & & \\
Total & 591.381 & 469 & & & \\
\hline
\end{tabular}

Note. ${ }^{*}$ Statistically significant at $\alpha=.05$.

Table 3 shows statistically significant differences in the parents' perceptions of primary/secondary students' learning according to the child's grade level $(F=20.236)$. To determine those statistically significant differences, Schiff's post hoc test was calculated. These results are shown in Table 4. 


\section{Table 4}

Schiff's Post Hoc Test Results of Parents' Perceptions Toward the Distance Learning Process According to Child's Grade Level

\begin{tabular}{llccc}
\hline & & & & \\
& Child's grade level & & & \\
& & & $S E$ & Sifference \\
\hline $1-4$ & $5-7$ & $-0.69537^{*}$ & 0.11983 & $.000^{*}$ \\
& $8-10$ & $-0.1395^{2}$ & 0.13551 & .589 \\
$5-7$ & $1-4$ & $0.69537^{*}$ & 0.11983 & $.000^{*}$ \\
& $8-10^{\mathrm{t}}$ & $0.555^{*}$ & 0.12163 & $.005^{*}$ \\
$8-10$ & $1-4$ & 0.13952 & 0.13551 & .589 \\
& $5-7$ & $-0.55585^{*}$ & 0.12163 & $.000^{*}$ \\
\hline
\end{tabular}

Note. ${ }^{*}$ Statistically significant at $\alpha=.05$.

Table 4 shows that statistically significant differences were in grades $5-7$, and then grades $8-10$, and finally grades 1-4. The results of grades 1-4 might be attributed to the sensitivity of this age group, a foundational stage for students. Students at this stage are children who lack independent learning skills. They need guided activities to acquire knowledge, skills, and attitudes, which they are not able to acquire without direct interaction with teachers and close monitoring. In addition, parents cannot teach their children at this age in the way that teachers do, due to their lack of sufficient teaching skills and competencies and appropriate ways to deal with the developmental needs of this age group. The results related to grades $5^{-10}$ can be attributed to the fact that children in this age group already have some self-learning skills and the ability to achieve learning goals with the help of teachers remotely, without the need to communicate with them face to face.

\section{Third Question}

To answer the third question-are there statistically significant differences at the level of significance $(\alpha=0.05)$ in the perceptions of parents of primary and secondary students in Jordan toward the distance learning process attributed to the variable of teacher's gender? -means and standard deviations were calculated. Table 5 shows these results according to the teacher's gender variable (male, female).

\section{Table 5}

Means and Standard Deviations of Parents' Perceptions Toward the Distance Learning Process According to Teacher's Gender Variable

\begin{tabular}{lll}
\hline Teacher's gender & $M$ & $S D$ \\
\hline Male & 2.8713 & 0.90181 \\
Female & 3.5528 & 1.13399 \\
\hline
\end{tabular}


Table 5 indicates differences between means according to the teacher's gender. To find out whether these differences are statistically significant, the independent samples $t$ test was calculated. The results are illustrated in Table 6 .

\section{Table 6}

Independent Samples $t$ Test Results of Parents' Perceptions Toward the Distance Learning Process According to Teacher's Gender Variable

\begin{tabular}{lccccc}
\hline & Variable & $F$ & Sig. & $t$ & $d f$ \\
\hline Teacher's gender & 15.496 & $.000^{*}$ & -6.345 & 195.346 \\
\hline
\end{tabular}

Note. ${ }^{*}$ Statistically significant at $\alpha=.05$.

Table 6 shows statistically significant differences in parents' perceptions toward distance learning according to the teacher's gender variable $(F=15.496)$, in favor of female teachers. This result can be attributed, based on the researchers' experiences in the educational field, to female teachers seeming to put forth more effort in the teaching process than males. In addition, female teachers, compared with male teachers, bear a greater responsibility and work to develop themselves by attending workshops and training courses related to the development of vocational, technological, and cognitive skills. These assumptions are based on higher rates of academic success achieved in female schools, compared with male schools, according to Jordan's Ministry of Education (2020a) statistics.

Regardless of the compatibility of the sample of this study, which included parents within the samples of previous studies that included teachers and students in universities, the results of this study differ from of Al-shboul et al.'s (2015) and Awad and Hilles's (2015) results, which demonstrate no statistically significant differences attributed to the gender variable.

\section{Fourth Question}

To answer the fourth question-are there statistically significant differences at the level of significance $(\alpha=0.05)$ in the perceptions of parents of primary/secondary students in Jordan toward the distance learning process attributed to the school type variable?-means and standard deviations were calculated. Table 7 shows these results according to the school type variable (public, private, UNRWA).

\section{Table 7}

Means and Standard Deviations of Parents' Perceptions Toward the Distance Learning Process According to School Type Variable

\begin{tabular}{lcc}
\hline \multicolumn{1}{r}{ School type } & $M$ & $S D$ \\
\hline Public & 2.9299 & 0.93945 \\
Private & 4.0052 & 1.07970 \\
UNRWA & 3.2500 & 0.98786 \\
\hline
\end{tabular}

Note. UNRWA = United Nations Relief and Works Agency

Table 7 illustrates apparent differences between means according to school type. To find out whether these differences are statistically significant, a one-way ANOVA test was calculated. The results are illustrated in Table 8. 


\section{Table 8}

One-Way ANOVA Results of Parents' Perceptions Toward the Distance Learning Process According to School Type Variable

\begin{tabular}{lccccl}
\hline \multicolumn{1}{c}{ Source } & Type III sum of squares & $d f$ & $M S$ & $F$ & Sig. \\
\hline Between groups & 120.098 & 2 & 60.049 & 59.503 & .000* $^{*}$ \\
Within groups & 471.283 & 467 & 1.009 & & \\
Total & 591.381 & 469 & & & \\
\hline
\end{tabular}

Note. ${ }^{*}$ Statistically significant at $\alpha=.05$.

Table 8 shows statistically significant differences in the of parents' perceptions according to the school type variable $(F=59.503)$. To determine which school type was favored, Schiff's post hoc test was calculated. The results are shown in Table 9.

\section{Table 9}

Schiff's Post Hoc Test Results of Parents' Perceptions Toward the Distance Learning Process According to School Type Variable

\begin{tabular}{llccc}
\hline & & & & \\
& School type variable & $M$ difference & $S E$ & Sig. \\
& & & & \\
\hline Public & Private & $-1.07537^{*}$ & 0.09925 & $.000^{*}$ \\
& UNRWA & -0.32014 & 0.14821 & .098 \\
\multirow{2}{*}{ Private } & Public & $1.07537^{*}$ & 0.09925 & $.000^{*}$ \\
& UNRWA & $0.75524^{*}$ & 0.15061 & $.000^{*}$ \\
& Public & 0.32014 & 0.14821 & .098 \\
& Private & $-0.755^{*}$ & 0.15061 & $.004^{*}$ \\
\hline
\end{tabular}

Note. UNRWA = United Nations Relief and Works Agency

* Statistically significant at $\alpha=.05$.

Table 9 shows statistically significant differences in favor of private schools, followed by UNRWA schools, and finally public schools. These results can be attributed to the implemented system of private educational institutions in Jordan and the supervision provided from the Department of Private Education (Ministry of Education, 2020a). Such supervision urges private schools to make great efforts, even in traditional, face-to-face learning, to create new opportunities for communication with parents for all levels, grades, and subjects. Compared with public and UNRWA schools, private schools work to sustain communication with parents via telephone and ensure that they follow the school's electronic webpages and social media and interact with them.

\section{Conclusion and Implications}

This study's aim was to investigate perceptions of parents of primary and secondary students in Jordan toward the distance learning process during the COVID-19 pandemic. The study results demonstrate 
that parents were moderately satisfied with the distance learning process. In addition, the results show statistically significant differences in the parents' perceptions to variables of child's grade level, teacher's gender, and school type. Because of the scarcity of such studies in Jordan, as a result of not applying this learning before the COVID-19 pandemic, researchers are encouraged to conduct more quantitative and qualitative research studies related to the perceptions of students, teachers, and stakeholders in the educational sector regarding the reality of distance learning and teaching processes in Jordanian schools and universities. Furthermore, further research should investigate which practices implemented in private schools versus public schools result in differences in perceptions for these types of schools.

This study can help decision makers, managers of educational institutions, and specialists in the educational sector learn how parents view distance education and how to improve its use in the future in a manner that suits students' needs. The authors expect that this study can inform decision makers and specialists in the educational sector about parents' perceptions of the distance learning process. Knowing these perceptions can give stakeholders opportunities to maximize the benefits of distance learning and reflect on the parents' perceptions regarding the current application of this teaching and learning avenue. 


\section{References}

Aboud, H. (2007). Computer in education. Wael Publishing House.

Al-Areifi, H., Qattait, G., \& Al-Khalayleh, H. (2016). Computer applications in educational administration. House of Culture for Publishing and Distribution.

Al-Arfaj, A., Khalil, Z., Al-Shura, M., \& Al-Khasawneh, M. (2012). Teaching techniques. Zamzam Publishers and Distributors.

Al-Ghannouchi, Q. (2010). The use of information and communication technology in education. Wael Publishing and Distribution House.

Al-Manizel, A., \& Al-Atoom, A. (2010). Research method in educational and psychological sciences. Enrichment for Publishing and Distribution.

Al-Mukhaini, M. (2017). Employing integrated education in designing educational websites. Dar AlSafa for Publishing and Distribution.

Al-Najem, Q. (2019). Distance education and future challenges. Journal of Islamic Research, 5(41), 131-160. https://search.mandumah.com/Record/1007065

Al-Rashidi, M. (2018). Distance learning. University Education House.

Al-Rawadiyah, S., Bani Domi, H., \& Al-Omari, O. (2014). Technology and teaching design. Zamzam Publishers and Distributors.

Al-Sajini, W., \& Khalil, H. (2017). Designing electronic curricula and courses via the Web. Al Masirah House for Distribution and Publishing.

Al-Sharman, A. (2015). Blended learning and reverse learning. Dar Al-Masirah.

Al-shboul, Q., Sabiote, C., \& Álvarez-Rodríguez, J. (2015). Professors' perceptions of distance education in virtual environments: The case of the education faculty of University of AlYarmouk (Jordan). Digital Education Review, 28, 145-162. https://doi.org/10.1344/der.2015.28.142-162

Al-Smadi, H. (2020). The impact of distance learning on the economics of education. Muta for Research and Studies-Humanities Series, 35(2), 27-50. https://xwww.mutah.edu.jo/darj/image2/35-2020-2H.pdf

Amer, T. (2013). Distance education and open education. Al-Yazouri Scientific House for Publishing and Distribution.

Aqel, K. (2014). Attitudes of faculty members in Jordanian public universities towards distance learning and its relationship to some variables. [Unpublished master's thesis]. University of Jordan.

Awad, M., \& Hilles, M. (2015). The attitude towards distance learning technology and its relationship to some variables among graduate students in Palestinian universities. Al-Aqsa University 
Journal-Humanities Series, 19(1), 220-256.

https://www.alaqsa.edu.ps/site_resources/aqsa_magazine/files/930.pdf

Bin Ahmed, K., Himyani. S., \& Houari, F. (2019). The possibility of materializing the distance education program in the faculty of economics, business, and management sciences at the University of Djelfa from the viewpoint of teachers. Journal of International Economics and Globalization, 2(4), 119-140. https://www.asjp.cerist.dz/en/article/124505

Hamaidi, D. (2008). Rural returning early childhood educators' and university professors' experiences with online courses: Phenomenological study. [Unpublished doctoral dissertation]. New Mexico State University.

Holmberg, B. (1983). Guided didactic conversation in distance education. In D. Sewart, D. Keegan, \& B. Holmberg (Eds.), Distance education: International perspectives (pp. 114-122). Croom Helm. DOI 10.1201/9781003033950-10

Holmberg, B. (1995). The sphere of distance education: Theory revisited. Retrieved June 6, 2020, from https://www.eric.ed.gov/ERICDocs/data/ericdocs2sql/content storage 01/0000019b/80/1 4/25/f8.pdf

Lever-Duffy, J., \& McDonald, J. (2018). Teaching and learning with technology (Y. M. Arouri, Trans.). Dar Al-Fikr.

Ministry of Education. (2020a). Achievements and projects of Department of Private Education. Retrieved November 5, 2020, from https://moe.gov.jo/ar/node/7500

Ministry of Education. (2020b). Initiatives. Retrieved June 6, 2020, from http://www.moe.gov.jo/ar/node/48

Ministry of Education. (2020c). Noorspace. Retrieved November 11, 2020, from https://moe.gov.jo/ar/node/62505

Rajadurai, J., Alias, N., Jaaffar, A., \& Hanafi, W. (2018). Learners' satisfaction and academic performance in open and distance learning (ODL) universities in Malaysia. Global Business and Management Research: An International Journal, 10(3), 511-523. http://ur.aeu.edu.my/id/eprint/459

Saadeh, J., \& Al-Sartawi, F. (2015). The use of computers and the Internet in the fields of education. Dar Al-Shorouk.

Schlosser, L., \& Simonson, M. (2015). Distance education: Definition and glossary of terms (N. Azmy, Trans.). Beirut Library. https://drive.google.com/file/d/oByzPnsLpa GBVUVCRjAyMzlidlU/view

UNESCO. (2002). Open and distance learning: Trends, policy and strategy consideration. Retrieved November 5, 2020, from https://unesdoc.unesco.org/ark:/48223/pfooo0128463 

Hamaidi, Arouri, Noufal, and Aldrou

\section{Athabasca}

University

(c) (1) 